\title{
The Cultural Practices of Modern Chinese Buddhism: Attuning the Dharma, by Francesca Tarocco
}

London: Routledge, 2007 | xii+I 83 pages | ISBN: 978-0-4I 537503-0 (hardback) £95.00 | ISBN 978-0-4I 5-37503-0 (softback) $£ 26.00$

In The Cultural Practices of Modern Buddhism, Francesca Tarocco examines how Buddhism and

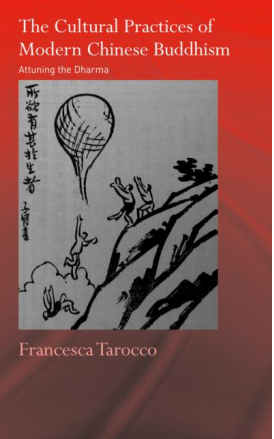
Buddhists in Mainland China (and in particular Shanghai) have attempted to utilize new forms of media and technology that emerged at various stages during the hundred years since the mid- to late nineteenth century. This book presents a survey, or an introduction to, rather than a comprehensive study of, the topic indicated by the title. The strength of the book is that it can provide emerging scholars who have similar interests with a starting point in a number of fields.

The book itself is divided into an Introductory section, which provides the theoretical background for her study, and two main parts. Part I deals mainly with print media, but also with Buddhist Societies, vegetarianism, and the ways in which Buddhism has been used to promote morality in prisons and for other political purposes. Part 2 focuses on music creation and new forms of distribution of music media.

The overarching theoretical premise behind Tarocco's study is her assertion that the interaction between China's ancient traditions and modernity allowed Buddhism to retain a pivotal role at the heart of Chinese religion, spirituality, ethics, culture, and even nationhood (3). Tarocco challenges the commonly accepted notion that Buddhism goes through periods of decline 
and revival (3). Instead, she claims that if we examine any specific period of supposed decline we find Buddhism remaining widespread, but perhaps appearing in different forms. That is to say, the non-institutional forms of Buddhism persist, and even dominate, despite a decline in the monastic order. The main cultural practices she examines include the wide-scale printing of Buddhist materials, the formation of Buddhist "modern societies," various ways Buddhist ideas were used in attempts to establish values for a new modern China and potentially for the world ( 15 ), and in the creation and distribution of music media (I 2).

The introductory chapter establishes her argument that Buddhism in China is a significant influence on cultural practices and in particular art and literature (I 2). It is a very credible claim, and Tarocco documents how in the past century or so Buddhism has engaged with rather than opposed new media and technology. Tarocco claims there was no decline of Buddhism from the late nineteenth century through to the I950s, or in the post-Mao era, and points to the use of modern technological media. She notes that while these periods are often considered to be periods of decline, there was a high degree of growth of Buddhism in these forms of cultural expression.

Tarocco argues that the established narrative of the decline and revival of Buddhism in China dating back as far as $700 \mathrm{CE}$ is a fallacy. She claims that through this entire period Buddhism, Buddhist ideas, and even members of the Buddhist clergy have always had a major influence on the nation's institutions and culture. Several factors have perpetuated the myth of decline and revival, including the fact that Buddhism possesses its own narrative of decline and revival. In addition, the idea has been embedded in Western studies of Buddhism from the time of the earliest Orientalist studies and there have been varying degrees of support for, and attacks on, Buddhism and Buddhist institutions in China over the centuries. Notwithstanding all of this, Tarocco claims that Buddhism has retained its influence on the Chinese people and even the Chinese political system over this entire period. While the twenty pages of this chapter do not force a reevaluation of Chinese Buddhist history, her argument should provoke further research.

Yet a theory of how cultural practices constitute "Buddhism" is lacking in Tarocco's argument. The claim that "Buddhist-inspired practices" flourished at times when monastic institutions are in decline does not necessarily mean that there was no overall decline in Buddhism during these periods. Therefore Tarocco needed to do more to demonstrate how these cultural practices were infused by Buddhism, and how they constitute Buddhism. Perhaps 
an argument like Yang's theory of red, black, and grey markets of religion ${ }^{1}$ would help contextualize "Buddhist-inspired practices" as a living form of Buddhism that continues to exist during periods when the monastic institutions have come under restrictions.

In part I, Tarocco claims that a range of "Buddhist-inspired activities" demonstrates that Buddhism retained a pivotal role from the beginning of the Taiping period in the late nineteenth to the early twentieth century, ending after World War Two and pre-Communist China (although she does occasionally discuss events post-1 949), a period in which, she claims, Buddhism is usually said to be in decline (25). The argument, as mentioned above, is that in times of Buddhist persecution, activity continues, but perhaps in less orthodox forms. She claims that during this period although religious institutions were banned at various times, the international spread of Buddhist scholars and utilisation of new mass media can hardly be described as a decline. One example of this was the inclusion of Buddhist practices and lectures in the prison system (26).

Tarocco argues that the widespread popularity of vegetarian restaurants in Shanghai stretching back to the I920s indicates a Buddhist influence on the city. It is not uncommon for people to believe there to be both health as well as spiritual benefits of eating vegetarian food. This is because in China vegetarianism is strongly linked to Buddhism (3I-34).

I found section I.2, Vegetarian Identities, to be thematically problematic. Despite Tarocco's concise and interesting parallel between Buddhists and vegetarianism in China, her discussion of Luo Jiajang and the Bodhi Societyis less concise. It is odd to tie them together under the same heading. Firstly, despite noting their interests in vegetarianism, Tarocco does little more to tie them in with the promotion of vegetarianism in Shanghai. And although they promoted Buddhism to a wider audience, they did not appear to do anything specifically in regards to vegetarianism. Tarocco notes that Luo Jiajang (I 864-I94I) was a "munificent benefactor of Buddhism," who gave "full financial support" for reprints of the Chinese Buddhist Canon. The Bodhi Society consisted of a group of individuals involved in both "educational and philanthropic" Buddhist goals. The main link between vegetarianism and different groups was that vegetarian restaurants were a place where the Bodhi Society and other Buddhist religious and political groups met (32). These in-

${ }^{1}$ Fenggang Yang, "Red, Black, and Grey Markets for Religion in China”, Sociological Quarterly 47, no. I (2006): 93-I 22. 
cluded publishing Buddhist and academic writings; Tarocco emphasizes their role in promoting morality in modern China. However much of this content does not relate to the title of this subsection.

The section on Taixu (1890-1947) is also problematic, as it fails to portray the importance of this figure. Taixu played an important part in the modernization of Buddhism in Shanghai, yet his significance for Taiwanese new Buddhist movements, most notably Ciji, Foguang Shan, and Fagushan, was largely overlooked. However Tarocco does link Taixu to the Foguang Shan later when discussing music (I 34). She also notes Taixu's contribution to renjian fojiao, a core belief of these movements in Taiwan (8I). However, it would have been useful for Tarocco to have dedicated an entire section to the discussion of this important figure; instead references to Tiaxu are spread throughout the book. Therefore reading the section which is explicitly on Taixu, one could easily miss the importance of this influential figure.

Tarocco describes how publishers and certain figures were involved in a publishing boom, including the reprinting of old sutras and various Buddhist canons, and also "new books by contemporary authors" (59). The era not only focused on publishing for a Chinese audience, but also in the dissemination of Buddhism to a wider international sphere (53-59). Different protagonists from, or living in, Shanghai were responsible for promoting Buddhism as a "force of civilization" (64).

Part 2 of the book focuses on the role of music during a similar, but slightly later period. Tarocco traces links to both (I) Western sources, such as western classical music, music used by Christian missionaries, and contemporary music, some of which had also arrived in China via Japan (I I6-23); and (2) Chinese sources, including specific Buddhist practices and other Chinese traditional musical practices (I23-28). Tarocco shows how the increased appreciation for Western Classical music also accompanied a similar growth in Chinese Classical music_-perhaps uncovering a theme that while learning new ideas from the West was important, the Chinese continued to see the importance and equal standing of their own traditions. Therefore, in terms of music, modernization and the introduction of Western ideas/technologies also led to increased appreciation for China's own counterparts. Despite Buddhist music and Buddhist themes in poetry and other forms of literature stretching back over a millennium, the use of Western ideas resulted in a "less lofty" or more mass consumable "genre" (I 28).

Tarocco jumps from the 1930 os to the 1980 in her discussion on the digital age ( $130-38)$. In this section the primary location for the production of 
digital Buddhist music is not Shanghai but rather Taiwan. The link that does remain is Xingyun, the founder of the Foguang Shan Buddhist movement, and his connection with Taixu and Shanghai prior to moving to Taiwan in I949 (I 34). In this section she focuses on the Foguang Shan movement as a specific group that has set out to utilize music for the teaching and spread of Buddhism, and also discusses the creation of karaoke recordings of Buddhist songs. However music created in Taiwan, often by Foguang Shan, has become ubiquitous in China. Once again these sections are interesting but she does not delve deeply into any of the topics.

Overall this book is a survey, rather than a detailed account, of the various cultural practices of Buddhism in China. Such a comprehensive account would require far more than I 83 pages. I also found two of the subsections in the first part of the book ("The Cultural Practices of Buddhist Modernity") confusing in relation to their subtitles. However Tarocco has provided scholars with a good starting point for more in-depth and specific studies. The strongest section is part 2 ("The Sound of Modern Buddhism"); here Tarocco presented a more comprehensive approach. Perhaps most interesting is Tarocco's account of how popular practices, such as vegetarianism, and the use of contemporary media to present Buddhist ideas, have been instrumental in shaping modern China.

Tenzin Mullin

University of Otago 